ISSN: 2238-8052

Volume 7, Número 2 (2018)

Movimentos Sociais \&

\title{
A AÇÃO COLETIVA: O DESAFIO DA MOBILIZAÇÃO
}

\author{
THE COLLECTIVE ACTION: THE CHALLENGE OF MOBILIZATION
}

Paulo Cesar Garré SILVA ${ }^{1}$

Artigo recebido em 23/10/2018 e aceito em 21/12/2018

Palavras-chave:

Ação coletiva;

Mobilização;

Movimento social;

Estrutura de oportunidades

políticas;

Repertório.

Keywords: Collective action; Mobilization; Social movement; Structure of political opportunities; Repertoire.

\section{R E S U M O}

O presente artigo analisa a ação coletiva a partir de uma pesquisa teórica, caracterizando-a e ao mesmo tempo identifica elementos que a distingue de um movimento social. 0 objetivo central desse estudo é analisar os fatores que favorecem a mobilização dos indivíduos em torno de uma ação coletiva. Esses fatores estão relacionados aos membros dos grupos, quando estes são estimulados à participação, ou às condições estruturais que motivam a participação dos indivíduos na ação de protesto. A ação coletiva é um processo contínuo que exige um repertório de ação que é continuamente adaptado e inovado para que possa favorecer a vitória dos desafiantes e a derrota dos desafiados.

\section{A B S T R A C T}

This paper analyzes collective action from a theoretical research, characterizing it and at the same time identifies elements that distinguish it from a social movement. The main objective of this study is to analyze the factors that favor the mobilization of individuals around a collective action. These factors are related to the members of the groups, when they are stimulated to participation, or to the structural conditions that motivate the participation of the individuals in the protest action. Collective action is an ongoing process that demands a repertoire of action that is continually adapted and innovated so that it can favor the victory of the challengers and the defeat of the challenged.

\section{INTRODUÇÃo}

O que faz as pessoas se mobilizarem em ações coletivas tem sido a preocupação de muitos cientistas sociais, cada qual com um instrumental para explicá-la e refutar teorias opostas ou discordantes. Não é objetivo deste artigo se posicionar a favor ou contra uma determinada teoria, mas antes refletir sobre a ação coletiva a partir de algumas perspectivas de análise e apontar questões, que se pensa, fundamentais para a reflexão sobre o processo de construção de uma ação coletiva.

É claro que uma ação coletiva não é construída da mesma forma que se constrói um automóvel, neste o encaixe das peças em seus devidos lugares é suficiente para construí-lo. A construção de uma ação coletiva não segue um manual que oriente o encaixe de suas peças, sua construção é dinâmica e

\footnotetext{
1 É professor da Educação Básica da Secretaria de Estado da Educação do Maranhão (SEDUC) e da Secretaria Municipal de Educação de São Luís (SEMED), Brasil. É graduado em Filosofia e Letras, mestre em Educação e doutorando em Ciências Sociais pela Universidade Federal do Maranhão (UFMA), Brasil. E-mail: paulogarre@yahoo.com.br (autor correspondente).
} 
muito frequentemente, imprevisível, pois fatores e atores estão constantemente se transformando no processo de interação que envolve a ação coletiva.

A ação coletiva não é uma via de mão única, muito menos de mão dupla. Há interesses múltiplos que permeiam as interações sociais no interior das ações coletivas, muito embora, frequentemente, as ações coletivas sejam apresentadas como um conflito em torno de duas posições antagônicas: de um lado, os desafiantes; do outro, os desafiados. Porém nenhum dos lados tem interesse homogêneo, mas em alguns momentos do conflito é possível que os interesses de cada lado se sincronizem e formem uma unidade, mesmo que seja provisória.

Manter a unidade, mesmo que aparente, é um desafio tanto para os desafiantes como para os desafiados. Tanto um lado como o outro tenta provocar a ruptura da unidade do adversário, pois sabem que a ruptura dessa unidade é um fator de enfraquecimento que pode levar a derrota no confronto com seu oponente. É claro que a unidade de um grupo envolvido num confronto não se constitui por si só, mas é decorrente de outros fatores que envolvem a mobilização, o que será abordado no segundo tópico deste artigo.

A ação coletiva também não possui uma caracterização unívoca, há diferentes formas e níveis de ação coletiva. No primeiro tópico deste artigo, tenta-se definir uma ação coletiva e fazer suas diferenciações tendo em vista seus objetivos. 0 que parece certo é que uma ação coletiva, como o próprio nome invoca, não é uma ação de um indivíduo isolado, mas uma ação de diversos indivíduos que objetivam algo em comum, mesmo que haja outros objetivos discordantes.

Definida a ação coletiva e analisado os fatores que motivam a mobilização em torno dela, faz-se conveniente que se reflita sobre as inovações de seus repertórios, uma vez que nenhuma ação coletiva se constrói sem o diálogo com as que lhes antecederam, da mesma forma que suas consequências se projetam para o futuro, sendo que outros atores possam reutilizar seus repertórios inovadores adaptando-os, ou melhor, reatualizando-os, ou mesmo desprezando-os devido a ineficácia experienciada anteriormente, isso é o que constitui o conteúdo do terceiro e último tópico deste artigo.

Essa análise tem seus limites dado a extensão do tema e da produção acadêmica em seu entorno, porém busca sintetizar ideias de autores que possam contribuir com a investigação e propor uma reflexão aos atores sociais envolvidos com a ação coletiva. Além disso, procura mostrar que as diversas teorias da ação coletiva não são excludentes, as lacunas deixadas por uma podem ser preenchidas por outra. A mobilização de recurso de Olson, por exemplo, não pode ser desconsiderada completamente, porém não dá conta da complexidade da natureza de uma ação coletiva, sendo que a relação custo-benefício não é o único fator relevante para estimular um indivíduo a participar de um protesto.

Por outro lado, a consciência de classe não é suficiente para motivar a ação de um indivíduo, uma vez que a consciência por si só não se transforma em ação, pois não há um determinismo que converta consciência de classe em ação, embora a consciência que o indivíduo tem de si e de sua 
posição social seja importante para motivá-lo a participar de uma ação coletiva que envolva a participação do grupo social com o qual se identifica. A consciência de classe, que é uma forma de construção de identidade, desconsidera questões importantes que não se situam exclusivamente dentro dos limites do conceito de classe, como as questões culturais e de gênero, que são fundamentais para fazer emergir, no indivíduo, sentimentos de pertencimento a determinado grupo, que são essenciais ao processo de construção de identidades individuais e coletivas, como aponta Axel Honneth.

Numa outra perspectiva, Tarrow defende que o surgimento de uma ação coletiva está relacionado diretamente com a fragilidade do sistema, sendo que fatores sociais e econômicos são insuficientes à promoção de uma ação coletiva sem que o sistema dê sinais de fragilidade, daí o conceito de estrutura de oportunidades políticas, que é quando o sistema abre brechas ou lacunas que são oportunidades de ação para os grupos opositores a ele. Embora não se possa negar que sinais de fragilidade do sistema sejam um convite aos protestos, não se pode desconsiderar outros fatores apontados anteriormente como importantes para a deflagração de ações coletivas, desse modo, percebe-se fragilidades e consistências nas teorias mobilizadas neste artigo, porém não é seu objeto aprofundar análises de construção e reconstrução teórica, mas antes seguir uma argumentação que subsidie uma reflexão acerca da mobilização da ação coletiva.

Por isso, considera-se que o referido artigo tem uma relevância significativa porque propõe uma reflexão sobre a mobilização em torno da ação coletiva num momento de crise dos movimentos sociais tidos progressistas e avanços de movimentos contrários aos direitos humanos, muitas vezes classificados como fascistas. Embora a análise não se reporte à ação coletiva específica, de esquerda ou de direita, mas é evidente que o campo de esquerda tem urgência em se reinventar, procurando novas formas de mobilização para enfrentar os desafios que se mostram intensos com o avanço dos movimentos de extrema direita, de natureza fascista.

\section{A AÇÃo COLETIVA}

Uma ação coletiva é caracterizada como uma ação de um grupo de pessoas que tem um objetivo comum, mesmo que haja objetivos individuais no interior dessa ação, o que faz as pessoas se organizar em grupo deve ser um objetivo compartilhado por todos. "Um propósito que de fato é característico da maioria das organizações, e com certeza de praticamente todas as organizações com um importante aspecto econômico, é a promoção dos interesses de seus membros" (OLSON, 1999, pp. 17-18). A ação coletiva é uma forma organizada que reivindica direitos, melhores condições de trabalho, de moradia, mudança da ordem social e econômica de uma sociedade, entre outras reivindicações. É importante ressaltar que a ação coletiva surge devido à ação individual não ser suficiente para os objetivos que se pretende alcançar. 
A ação coletiva não é um fenômeno contemporâneo, embora que os movimentos sociais como conhecemos hoje seja um evento moderno. É importante compreender que eles empreendem novos repertórios à ação coletiva, mas também fazem uso de repertórios tradicionais. Thompson, em seu livro Costumes em comum, analisa os costumes na Inglaterra do século XVIII e relata várias formas de protestos, entre os quais os motins da fome. Neste caso ele diz que para essa questão específica (da fome) não há apenas uma forma de ação coletiva, há uma variedade de repertório que poderia ser utilizada. "Nem a rebelião precisa ser a única ou a mais óbvia forma de ação coletiva - pode haver alternativas, como petições em massa junto às autoridades, jejuns, sacrifícios e orações, inspeções até as casas dos ricos ou migrações de aldeias inteiras" (THOMPSON, 1998, p. 206). Estas são formas de ação coletiva que ainda são utilizadas (com algumas reformulações ou adaptações), umas mais agressivas às estruturas do poder, outras buscando vias alternativas que suavizam o confronto ou evitam-no.

Essas manifestações relatadas por Thompson estão na origem dos movimentos sociais modernos, sendo que a Inglaterra foi um dos berços de seu surgimento, isso não quer dizer que antes as pessoas não protestavam, mas que foi no século XVIII que as manifestações alcançaram um nível mais elaborado e de maiores amplitudes, conseguindo proporcionar maiores impactos e alcançando objetivos de forma mais eficazes.

Embora os seres humanos sempre tenham encontrado maneira de mostrar seu desagrado, o movimento social, tal como hoje o reconhecemos, surgiu no mundo moderno. Podemos mesmo dizer que surgiu na Grã-Bretanha e nos Estados Unidos, no final do século XVIII, em parte para tirar vantagens de parlamentos cada vez mais poderosos fundados na ideia de cidadania [...]. Essas novas arenas contribuíram ainda mais do que a urbanização para o nascimento do movimento social. Tal como ocorreria mais tarde em outros países, os movimentos sociais exigiam direitos e reconhecimento para grupos que estavam excluídos da participação política, mas sentiam ser parte da nação (JASPER, 2016, p. 38).

Os movimentos sociais surgem como uma forma organizada de se contrapor ao sistema de poder, os quais eram organizavam para reivindicar direitos e exigir o reconhecimento de grupos sociais como integrantes da sociedade. Os movimentos sociais não surgem como apolíticos, mas como organização com certo grau de poder político que se caracteriza por possuir força dentro do sistema político, o qual deve ser levado a sério. A ação coletiva dos movimentos sociais vai ganhando legitimidade à medida que o Estado se fortalece e organiza, em torno de si, uma teia de relações de trabalho para garantir a sua própria autodefesa num mundo que se apresenta com perspectivas de luta contínua para a manutenção do poder.

A expansão do Estado nacional é um dos fatores que alavanca a formação dos movimentos sociais, uma vez que o Estado lança mão de recursos que vão favorecer a formação dos movimentos sociais. Além dos recursos técnicos, como os meios de comunicação, o Estado viabiliza o surgimento de uma classe de trabalhadores que tem um potencial de organização muito elevado. Por outro lado, o 
Estado tinha a função de manter a ordem, para isso devia conciliar interesses opostos quando se via diante de uma ação coletiva reivindicativa, assim lançava mão de recompensas para conciliar os grupos discordantes. Dessa forma, o Estado, ao criar as condições para sua expansão, cria também as condições para as organizações sociais se manifestarem e construírem pautas reivindicativas que podem abalar a própria organização do Estado nacional.

\begin{abstract}
Esses esforços na construção do Estado não pretendiam apoiar a mobilização - bem o contrário. Mas proporcionaram meios de comunicação através dos quais a opinião pôde ser mobilizada, criaram uma classe de homens com experiência em negócios públicos e conduziram a cobranças financeiras de cidadãos que nem sempre estavam dispostos a pagar. Além disso, um Estado que assumiu a responsabilidade de manter a ordem tinha que regular as relações entre os grupos e isso significou criar um arcabouço legal para a associação e também estabelecer mecanismos legais mais sutis para o controle social do que as cacetadas do exército ou da polícia (TARROW, 2009, p. 21).
\end{abstract}

O Estado nacional cria involuntariamente as condições para o surgimento do movimento social, dando-lhe um espaço de ação e atuação dentro de um sistema estatal que pregava a construção de uma cidadania livre e democrática. Na defesa desses princípios, os movimentos sociais se organizam para cobrar do Estado o seu cumprimento, assim os movimentos fazem dos princípios supostamente defendidos pelo Estado suas bandeiras de luta, pondo o Estado numa dicotomia entre a repressão e a tolerância, se reprime os movimentos está, teoricamente, reprimindo a si mesmo, mas se não reprime, corre o risco de ser derrotado. É usufruindo da natureza ambígua do Estado que o movimento social cresce e se fortalece.

É importante observar que a ação coletiva, ao longo do tempo, não é uma atitude impulsiva, sem reflexão e sem estratégia. Geralmente, são respostas que envolvem sentimentos emotivos, mas também racionais que permitem aos autores da ação analisar o contexto e decidir o momento propício da ação ser deflagrada, como no caso dos motins da fome, que "o levante deve ocorrer antes que as pessoas fiquem muito enfraquecidas, o que talvez pressuponha uma estimativa prévia e vigilante do abastecimento e dos preços do mercado" (THOMPSON, 1998, p. 206). Os autores de uma ação coletiva vislumbram perspectivas de vitória, pois reconhecem seus poderes e suas capacidades de leitura da realidade, por isso agem com certa racionalidade, embora a ação possa envolver outros sentimentos, como certamente envolve.

Os motins são geralmente uma resposta racional, que não acontece entre os indefesos ou sem esperança, mas entre aqueles grupos que se sentem com um pouco de poder para tomar os víveres de que precisam quando os preços vão às alturas, os empregos desaparecem e eles veem o seu suprimento de alimentos básicos ser exportado (THOMPSON, 1998, p. 207).

A ação coletiva ocorre objetivando um fim, ela não acontece num vazio. Uma dada situação não determina a modalidade da ação coletiva que pode confrontá-la, nem mesmo que deva existir uma ação coletiva para confrontá-la. A ação coletiva é sempre uma reação de um grupo a uma determinada 
situação, o qual analisa a melhor forma de agir, isso não garante a vitória da ação porque o confronto envolve relações de poder e no embate entre os desafiantes e os desafiados essas relações vão tomando forma e se configurando favoráveis a uns em detrimento de outros, mas é bem provável que nem um dos lados consiga seus objetivos de forma plena, isto porque é possível que ocorram concessões tanto de um lado como de outro, a não ser que a ação coletiva rompa com o sistema de concessões e transforme radicalmente o sistema de poder.

Para alguns autores, quando uma ação coletiva transforma a estrutura do sistema de poder, ela deixa de ser simplesmente uma ação coletiva para transformar-se em movimento social. Seguindo esse raciocínio, pode-se dizer que todo movimento social é uma ação coletiva, mas nem toda ação coletiva pode ser considerada um movimentos social. Segundo Alan Touraine, um movimento social se caracteriza como um movimento que impõe mudanças estruturais na ordem social e econômica da sociedade, só quando um movimento tem essa característica que pode ser considerado como movimento social.

É necessário não aplicar a noção de movimentos sociais a qualquer tipo de ação coletiva, conflito ou iniciativa política [...] a sabedoria residiria em reservar o emprego da categoria 'movimentos sociais' ao conjunto dos fenômenos que, de fato, receberam esse nome no decorrer de uma longa tradição histórica. 0 essencial, aqui, é reservar a ideia de movimento social a uma ação coletiva que coloca em causa um modo de dominação social generalizada (TOURAINE, 2016, p. 18).

Assim, uma ação coletiva que não ultrapassa a reivindicação localizada de um setor social (produtivo ou de serviço), não põe em xeque o sistema de dominação e não é capaz de ruir a estrutura do sistema de poder vigente. Quando isso não acontece, as reivindicações da ação coletiva se concentram em concessões dentro do próprio sistema, impondo, no máximo, reformas que não abalam a estrutura do sistema de dominação. Uma ação coletiva deste nível é a expressão de crise do sistema e a resposta a ela é dada, frequentemente, com reformas dentro do próprio sistema, sendo que ela ajuda o próprio sistema a se reorganizar tendo em vista os ciclos de crise que são comuns dentro de qualquer sistema.

Os movimentos reivindicativos são sintomáticos de crises do sistema de poder, mas a natureza de suas reivindicações pode ser de dois tipos: as que podem ser solucionadas dentro do próprio sistema, sem abalar sua estrutura; e as que não são solucionadas dentro do sistema, pois suas soluções exigem rupturas estruturais. As primeiras exigem "melhorias" do sistema para garantir as reivindicações dos grupos; as outras não cabem no sistema, exigem transformações profundas que não são possíveis dentro do próprio sistema. Ações coletivas ou ativismos localizados que não conseguem romper os limites locais não põe em xeque o sistema de poder, mas isso não quer dizer que esses ativismos sejam sempre dessa natureza, há os que rompem as barreiras locais e estabelecem contatos mais amplos e críticas mais aprofundadas que abalam as estruturas do sistema de poder, quando isso acontece, $\mathrm{o}$ ativismo passa a ser considerado movimento social. 
Os movimentos sociais, de sua parte, seriam uma modalidade especialmente crítica e ambiciosa de ativismo social, distinta de ativismos 'paroquiais'. Estes encaminham reivindicações pontuais, sem articulá-las com questionamentos mais profundos, relativos a problemas nacionais e internacionais, e sem construir pontes entre a conjuntura, cujo domínio não ultrapassam, e as estruturas, que não chegam a tematizar (SOUZA, 2006, p. 278).

O ativismo é uma forma de ação coletiva que se caracteriza como uma ação duradora e contínua, podendo ter uma atuação local, nacional ou internacional. Nem todo ativismo local pode ser considerado "paroquial", uma vez que há movimentos que iniciam localmente, mas se expandem construindo articulações com outros movimentos e, por fim, adquirem características mais amplas de contestação estrutural, rompendo com os limites locais. Por isso, "um ativismo de base local pode ter uma agenda manifesta ou latente bastante crítica. E mais: um ativismo de base local pode ter como veículo de protesto manifestações culturais, em vez de ser, em sentido banal, 'reivindicativo'” (SOUZA, 2006, p. 280), quando isso acontece, como foi dito anteriormente, ele pode se tornar um movimento social.

Um movimento social é tido como uma ação coletiva que carrega em sua gênese um caráter de conflito, porém "somente a presença de um conflito não basta para qualificar uma ação coletiva como movimento social" (MELUCCI, 2001, p. 36), é necessário ir além e cumprir outras exigências. "Um movimento social deve cumprir três condições: romper as regras do jogo, propor objetivos não negociáveis e colocar em questão a legitimidade do poder" (MELUCCI, 2001, p. 35), portanto, um movimento social não expressa simplesmente um conflito, mas põe em evidência a legitimidade do poder, é uma luta empreendida que sai das fronteiras do negociável para disputar o comando dentro de um sistema simbólico e político.

O movimento social não ocorre fora de um sistema simbólico, a disputa travada entre os desafiantes e os desafiados se dá dentro de um contexto cultural, em que ambos dialogam por compartilharem, até certo ponto, de um mesmo sistema de representação, que faz possível a disputa. “Um movimento social é a combinação de um conflito com um adversário social organizado e da referência comum dos dois adversários a um mecanismo cultural sem o qual os adversários se enfrentariam" (TOURAINE, 2016, p. 19), assim, a disputa ocorre dentro de um sistema simbólico, isto é, dentro do âmbito de uma cultura compartilhada pelos adversários, é justamente esse sistema de representação que está em disputa, é a sua possibilidade de transformação que está em questão.

A ação coletiva não ocorre sem interação, a qual só é possível devido aos desafiantes e desafiados comungarem do mesmo sistema de representação, é claro que eles se diferenciam também em consequência da forma que se relacionam dentro desse sistema, ambos com representatividades distintas dentro do mesmo sistema. Cada qual disputa a simpatia da sociedade que é expressa na forma de solidariedade à sua causa, o desafio não é dirigido apenas a uma classe de opositores, além dos lados que se opõem existem os agentes sociais que não estão imbricados na disputa, mas o apoio 
deles faz parte do conflito, uma vez que sua solidariedade é fundamental para a vitória de um dos lados. Por isso, "a eficácia política de um ativismo repousa, largamente, em sua capacidade de obter apoio de diferentes tipos e granjear simpatia da opinião pública a partir de uma bem-sucedida articulação de escalas" (SOUZA, 2006, p. 306). Ou seja, a vitória de uma ação coletiva depende da sua capacidade comunicativa de apresentar suas reivindicações à sociedade e ser apoiada por ela, quer dizer, por parte expressiva dela.

Em vez de ver os movimentos sociais como expressões de extremismo, privação e violência, eles são mais bem definidos como desafios coletivos baseados em objetivos comuns e solidariedade social numa interação sustentada com as elites, opositores e autoridades (TARROW, 2009, p. 21).

A solidariedade social, sendo favorável aos desafiantes, dá um impulso à ação coletiva e estimula outros setores a fazer parte do movimento, que antes poderia estar restrita a um determinado grupo. A ampliação do conflito dá novas perspectivas de ação aos desafiantes, que encorajados pela solidariedade social dos demais grupos sociais, podem vislumbrar vitória frente aos desafiados. Por outro lado, se a solidariedade social for favorável aos desafiados, estes agem fortemente para derrotar os desafiantes, que sem apoio social, ou radicalizam suas ações ou tentam uma reconciliação com os desafiados.

O movimento social só ganha legitimidade quando faz surgir uma identidade entre os participantes do conflito, a qual passa a ser compartilhada também pelos sujeitos sociais que estão fora do conflito e não compõem o grupo social formador da ação coletiva, mas se sensibilizam com a causa desse grupo. "O surgimento de movimentos sociais depende da existência de uma semântica coletiva que permite interpretar as experiências de desapontamento pessoal como algo que afeta não só o eu individual mas também um círculo de muitos outros sujeitos" (HONNETH, 2009, p. 258). A identidade coletiva faz com que os participantes da ação coletiva comunguem, pelo menos em parte, dos mesmos ideais, se sintam identificados com os objetivos da ação, compartilhando os mesmos interesses. Essa identidade não se restringe ao grupo, mas também aos indivíduos que se solidarizam com os participantes da ação coletiva por se identificarem com sua luta.

A identidade também está relacionada ao território, ao ambiente de vida e luta, uma vez que todo movimento se situa num determinado espaço e luta por sua ampliação, seja numa dimensão social, política ou geográfica. "Os diferentes movimentos sociais re-significam o espaço e, assim, com novos signos grafam a terra, geografam, reinventando a sociedade" (GONÇALVES, 2006, p. 21) e a si mesmos, num processo de construção de identidade, a qual não se configura como estática, mas num processo contínuo de transformação, num devir. "Afinal, movimento é, literalmente, mudança de lugar e, assim, todo movimento social é, de alguma forma, em maior ou menor grau, portador de uma outra configuração social possível. (GONÇALVES, 2006, p. 21), ou seja, uma outra forma de pensar, de se relacionar entre si e com a natureza. 
A identidade construída em torno de uma coletividade não faz do indivíduo um ser de única identidade. A identidade coletiva faz os indivíduos compartilhar sentimentos e valores, mas não elimina sentimentos e pensamentos divergentes entre os membros do grupo e também entre seus apoiadores, os quais se solidarizam com suas reivindicações, mas, certamente, não compartilham com outros pensamentos do grupo ou de integrantes do grupo. A identidade coletiva é construída a partir do compartilhamento de uma identidade entre as várias que um indivíduo pode possuir. "O sujeito assume identidades que não são unificadas ao redor de um 'eu' coerente. Dentro de nós há identidades contraditórias, empurrando em diferentes direções, de tal modo que nossas identificações estão continuamente deslocadas" (HALL, 2006, p. 13), ou seja, as identidades são construídas num processo contínuo de aceitação e negação de processos culturais.

Os sistemas culturais mudam, assim como mudam as identidades, às quais são construídas dentro desses sistemas, sendo que "à medida em que os sistemas de significação e representação cultural se multiplicam, somos confrontados por uma multiplicidade desconcertante e cambiante de identidades possíveis, com cada uma das quais poderíamos nos identificar - ao menos temporariamente (HALL, 2006, p. 13), essa identificação ocorre a partir de um reconhecimento de si e de suas possibilidades de ser. A luta de uma identidade por reconhecimento se torna exitosa quando recebe a solidariedade social, isso provoca mudanças na estrutura da ordem simbólica da sociedade, uma vez que a identidade passa a ser reconhecida coletivamente, o que implica uma transformação na estrutura simbólica da sociedade.

A questão da identidade do movimento social não é objeto central deste artigo, ela é importante para compreender que há perspectivas diferenciadas de interpretação da ação coletiva e nem sempre uma ação coletiva pode ser considerada como movimento social. Não se quer aqui identificar os limites conceituais entre uma ação coletiva e um movimento social, mas chamar a atenção para a existência desses limites e que há perspectivas discordantes acerca desses limites, mas o que é importante aqui é a ação coletiva de uma forma geral, não especificamente enquanto movimento social, mas também enquanto movimento social. Que toda ação coletiva, independentemente de ser considerada movimento social, possui características que fazem dela uma forma de protesto que põe em xeque o sistema de dominação ou, por outro lado, intensifica a dominação. 0 seu desenrolar e a forma de resposta às reivindicações é que vão caracterizá-la como movimento social ou não. Mas é certo que o desafio maior da ação coletiva é a sua mobilização e talvez o seu sucesso que a caracterizará como movimento social ou apenas como uma ação coletiva sem maiores contestações ao sistema de dominação social.

É importante destacar que a análise dos movimentos sociais não se dá de forma unidimensional, uma vez que este objeto é multifacetado, ele pode ser visto a partir de diferentes perspectivas, ressaltando aspectos: social, político, histórico, geográfico e filosófico, pelo menos. Quanto mais uma análise busca compreender os movimentos sociais a partir de múltiplas 
perspectivas, isto é, de forma interdisciplinar, mais capaz será de compreendê-los como um objeto dinâmico que poderá ser visto por múltiplos olhares, que não constitui monopólio dos cientistas sociais, mas estão abertos a diversas possibilidades de interpretação e análise.

Os movimentos sociais constroem estruturas, desenvolvem processos, organizam e dominam territórios das mais diversas formas. Os movimentos são formas de organização social e, principalmente, os sociólogos, historiadores e cientistas políticos se dedicam a estudá-los há muito mais tempo que os geógrafos (FERNANDES, 2000, p. 60).

O estudo dos movimentos sociais se apresenta com uma demanda interdisciplinar, isso quer dizer que ele exige do cientista um esforço de compreensão que não se esgota a partir de um campo de análise, é necessário compreender esse objeto de análise além dos limites do social. Dessa forma, há exigências de novas possibilidades de reclassificá-lo, uma vez que alguns movimentos assumem novas relações com o espaço, daí a possibilidade de uma nova classificação. "Movimentos sociais que têm o espaço ou o território como trunfos, organizam suas formas e dimensionam-se a partir desse referencial" (FERNANDES, 2000, p. 61), por isso sua conceituação se amplia, buscando novas significações. "O conceito de movimento socioespacial é amplo, porque envolve as diferentes dimensões do espaço geográfico: social, político, econômico etc." (FERNANDES, 2000, p. 61). Não há como restringir a análise dos movimentos sociais há um campo específico de conhecimento, uma vez que esse fenômeno rompe limites disciplinares.

Os movimentos sociais apresentam-se como um objeto rebelde a qualquer tentativa de definição simples. Às vezes fugazes, eles podem ganhar permanências; microlocais, podem ampliar seus raios de ação; tematizam questões fortemente diferenciadas: do direito de propriedade à condição de gênero e de raça, passando pelo acesso a bens de consumo coletivo e à degradação ambiental (BITOUN, 1993, pp. 135-136).

Por isso, os cientistas que se propõem analisar um movimento social devem estar atentos às suas dinâmicas que, geralmente, não se conformam dentro de limites confortáveis de controle e dominação de um único campo de conhecimento. Esses cientistas encontram cada vez mais dificuldades de apreender o fenômeno da ação coletiva quando não buscam recursos que ampliem suas perspectivas de análise, sendo que a mobilização em torno de uma causa é um dos mais intrigantes desafios aos estudiosos da ação coletiva.

O sucesso da mobilização de uma ação coletiva parece ser um forte indicativo de que ela pode se converter em movimento social, dessa forma uma ação coletiva nem sempre nasce como movimento social, ela se tornar um movimento social à medida que seu conteúdo reivindicativo possa desencadear uma transformação no sistema de dominação ao qual se opõe. Nesse sentido, é importante analisar os fatores que favorecem a mobilização das pessoas em torno de uma ação coletiva. Qual a importância das lideranças nesse processo e quais aspectos culturais favorecem a 
mobilização em torno de um objetivo comum, se apenas esse objetivo comum é suficiente para mobilizar as pessoas em torno dele, enfim, o que faz alguns movimentos serem vitoriosos e outros não. 0 que de fato favorece a mobilização em torno de uma ação coletiva, o que faz as pessoas saírem de seu conforto e aderirem a um movimento reivindicativo ou, caso contrário, a ficarem no conforto de suas casas ou trabalho e não se mobilizarem em torno da ação reivindicativa.

\section{FATORES DE MOBILIZAÇÃo DA AÇÃo COLETIVA}

A mobilização das pessoas para uma ação coletiva é o aspecto mais desafiador para os seus líderes e envolve uma série de estratégias e situações contextuais que influenciam na adesão ou não à ação coletiva. Embora a ação coletiva tenha como objetivo o interesse comum do grupo, isso não é suficiente para garantir a mobilização dos membros dos grupos para participar da ação. Para uma ação coletiva ser exitosa são necessárias estratégias que possam atingir e sensibilizar a maior parte dos membros a participar do movimento reivindicativo, mas não há nada que garanta a participação de um membro submetido às estratégias de mobilização, é necessária a análise de várias variáveis para explicar a participação coletiva numa ação contestatória.

Não é suficiente a existência de um benefício comum para mobilizar os integrantes de um grupo para a participação numa ação coletiva, Olson (1999, p.34) analisa que essa participação tem sempre uma relação de custo-benefício. Qualquer participante de uma ação coletiva leva em consideração o custo da ação correlacionado com o benefício a ser adquirido. Se há uma análise favorável aos benefícios, a chance de participação é mais elevada, caso inverso a possibilidade de adesão à ação se reduz. Não se pode negar que os benefícios de uma ação coletiva são repassados de forma igualitária para todos os membros do grupo, enquanto que isso não acontece com o ônus, pois nem todos arcaram com os custos da ação coletiva. Isso faz com que quem não teve nenhum ônus na ação coletiva ganhe o bônus igual a quem teve um ônus elevado, esse é um fator que favorece a não adesão à ação coletiva por parte de membros dos grupos, pois analisam que os benefícios serão maiores para quem não participa da ação coletiva, que terá parte apenas no bônus sem se comprometer com o ônus.

A relação de custo-benefício de uma ação coletiva envolve vários fatores, desde o tamanho do grupo até os custos da ação propriamente dita, uma vez que podem aumentar conforme a reação do grupo desafiado. A forma de reação do grupo questionado (um governo, uma empresa) altera a relação de custo-benefício da ação coletiva, essa relação interfere na adesão dos membros à ação coletiva. A relação custo benefício sofre alterações no decorrer da ação, à medida que os custos da ação aumentam, o benefício coletivo da ação diminui. Além do aumento do custo da ação, a possibilidade de alcançar o benefício pretendido em sua integralidade também diminui, então, à proporção que a ação coletiva se prolonga o benefício coletivo tende a diminuir, a não ser que aconteça um aumento da 
adesão à ação coletiva para que o custo da ação seja diminuída individualmente para cada participante.

Embora a relação custo benefício da ação coletiva não seja negada pelos críticos de Olson, a adesão à ação coletiva não se restringe a esse cálculo econômico. A mobilização em torno de uma ação coletiva envolve outros elementos que não podem ser negligenciados em qualquer análise de uma mobilização em torno de uma ação coletiva. É claro que toda ação coletiva envolve custos, mas a sua relação com os benefícios não é o único fator motivador para um membro de um grupo fazer parte de uma ação coletiva.

[...] movimentos sociais não surgem pela simples presença de desigualdade, nem resultam diretamente de cálculos de interesses ou valores. As mobilizações envolvem tanto a ação estratégica, crucial para o controle sobre bens e recursos que sustentam a ação coletiva, quanto a formação de solidariedades e identidades coletivas (ALONSO, 2009, p 72).

A formação de uma ação coletiva não ocorre de forma espontânea, os motivos que levam a sua construção não se resumem a um aspecto apenas. A percepção da injustiça pode ser um fator importante para a deflagração de uma ação coletiva, mas, às vezes, não é suficiente, haja vista que existem várias situações de injustiça que não geram uma ação coletiva, mas por outro lado, é possível observar que a percepção da injustiça é fundamental para o surgimento da ação coletiva, pois "aqueles que protestam fazem isso porque seu senso de justiça foi ofendido" (BOLTANSKI, 2001, p. 22). Isso não quer dizer que toda ofensa ao senso de justiça de um grupo gere uma ação coletiva, mas é importante compreender que, geralmente, esse aspecto está presente numa ação coletiva.

É claro que esse embate só será definido no transcorrer da disputa em torno dessa compreensão do que seja justo. Nesse caso, o que está em disputa não é apenas o interesse de um determinado grupo, mas uma forma de pensar e definir o que seja a justiça. Mas a deflagração de uma ação coletiva não ocorre apenas pelo confronto em torno do conceito de justiça, mas porque uma série de fatores confluíu em direção à formação do conflito. 0 contexto de publicização da suposta ofensa ao senso de justiça do grupo é importante para que ecoe entre os seus membros e também fora do grupo e torne possível a construção de solidariedade social à causa do grupo. É o que os marxistas nomeiam de realidade objetiva favorável e o que outros teóricos chamam de estrutura das oportunidades políticas, isso quer dizer que o contexto político de deflagração de um protesto foi favorável aos desafiantes que no decorrer do embate produziram uma gramática capaz de convencer a sociedade da legitimidade de seu protesto.

[...] para tentar construir uma gramática - entendida como um conjunto de coações que se impõe a todos - de protesto contra a injustiça e a acusação que lhe é inerente. Visto que, para exigir reparação, quem protesta contra a injustiça que lhe foi causada deve necessariamente designar seu autor e, portanto, iniciar um processo de acusação que aquele a quem se destina a acusação pode também destacá-la como uma injustiça. 
Nestes casos não se pode saber a priori quem é o perseguidor e quem é o perseguido. (BOLTANSKI, 2001, pp. 22-23).

Uma ação coletiva instaura um conflito que se desenvolve como disputa em torne de concepções de justiça e de verdade. 0 veredito não é conhecido antes do encerramento do conflito, pois é construído no desenrolar das ações e reações do movimento contestador. A luta pela definição da justiça e da verdade se constitui como relações de poder, neste caso a justiça e a verdade não são entidades objetivas que carecem de desvelamento, mas antes são construções que envolvem o poder que cada grupo tem de convencer e construir solidariedades e identidades sociais dentro e fora de seu grupo, nesse processo o grupo vai adicionando poder à sua narrativa, ao seu discurso, sendo que é no embate das relações de poder entre os grupos que se constroem as verdades e as concepções de justiça.

Mas a justiça pode ser entendida em função de perspectivas distintas dos movimentos reivindicativo, sendo que há dois polos de atuação dos movimentos reivindicatórios progressistas, de um lado, os que lutam por redistribuição; do outro, os que buscam reconhecimento. Para Fraser, essa antítese é falsa, pois "justiça, hoje, requer tanto redistribuição quanto reconhecimento; nenhum deles , sozinho é suficiente" (FRASER, 2007, p. 103), ou seja, a justiça não possui apenas uma dimensão socioeconômica, mas também moral, de reconhecimento. Não é suficiente apenas redistribuir a renda, é necessário reconhecer cada grupo como portador de dignidade e de direito que não podem ser violados, cada identidade deve ser respeitada em sua integridade. A compreensão de que a luta por redistribuição e reconhecimento forma uma unidade de luta é um fator importante para a mobilização, uma vez que o distanciamento desses dois polos enfraquece o poder dos movimentos contestatórios.

Dessa forma, uma ação coletiva é um empreendimento que põe em movimento as relações sociais de poder, é no seu desenvolver que essas relações podem se configurar favoráveis aos desafiantes ou aos desafiados. É importante que aos desafiantes cumpre a instauração de uma nova verdade ou, pelo menos, a modificação de aspectos da verdade estabelecida e defendida pelos desafiados. Uma ação coletiva põe em movimento as relações de poder em torno das disputas discursivas, as quais definem conceitos que estão em disputa. Os conceitos não possuem suas verdades em si mesmos, elas dependem da força do discurso que a profere, força simbólica e representativa do grupo que a produziu.

O importante, creio, é que a verdade não existe fora do poder ou sem poder [...]. A verdade é deste mundo; ela é produzida nele graças a múltiplas coerções e nele produz efeitos regulamentados de poder. Cada sociedade possui seu regime de verdade, sua 'política geral' de verdade: isto é, os tipos de discursos que ela acolhe e faz funcionar como verdadeiros; os mecanismos e as instâncias que permitem distinguir os enunciados verdadeiros dos falsos (FOUCAULT, 2013, pp. 51-52).

Uma ação coletiva reivindicativa põe em xeque o regime de verdade e a política geral de uma sociedade. É contra seu regime e sua política que ela se constrói, mas isso nem sempre parece evidente 
aos membros do grupo, uma vez que o interesse em transformar um regime de poder pode parecer distante do interesse dos membros de um determinado grupo, por isso esse objetivo não é o mais explícito para o grupo. A ação coletiva se constrói, embora num primeiro momento, por interesses individuais comuns mais perceptíveis aos membros do grupo. No decorrer do processo, os interesses políticos podem ser evidenciados e as estruturas de dominação social do sistema desveladas, podendo o confronto ganhar proporções de transformação estrutural.

A mobilização em torno da ação coletiva, como já foi dito, não depende apenas de uma relação custo benefício, nem tampouco do questionamento do senso de justiça do grupo, mas esses dois aspectos são importantes para a mobilização coletiva. A construção da identidade em torno da reivindicação do grupo é outro fator importante, uma vez que ninguém se dispõe a lutar por uma causa se não se identifica com esta. Esta identidade não ocorre apenas por um aspecto de consciência de justiça, portanto, de um aspecto racional, mas também numa perspectiva emocional, dos sentimentos de pertencimento a um determinado grupo ou até mesmo de solidariedade a esse grupo, sendo que a causa do grupo, em particular, conseguiu se expandir para uma causa social mais geral.

Quando a causa do grupo se expande para a sociedade em geral, isso ocorre devido à solidariedade social, ou seja, uma reivindicação que era local ganha status geral e deixa de ser uma ação coletiva localizada para se tornar um movimento social com potencialidade para transformar o 'regime de verdade', ou a estrutura de dominação social de uma sociedade. "O surgimento de movimentos sociais depende da existência de uma semântica coletiva que permite interpretar as experiências de desapontamento pessoal como algo que afeta não só o eu individual mas também um círculo de muitos outros sujeitos" (HONNETH, 2009, p. 258). A interpretação acerca das causas do conflito deixa de ser monopólio de um grupo para ser compartilhada por uma parcela significativa da sociedade, dando à ação coletiva uma dimensão que antes não tinha, quer dizer uma dimensão de transformação social.

O discurso do grupo ganha repercussão entre os demais grupos sociais, despertando um sentimento que estava aparentemente adormecido nos membros desses grupos, fazendo emergir uma revolta que, ocultamente, vinha sendo construída no interior de cada indivíduo, que veio a tona a partir do episódio conflitivo de um grupo específico. Há formas não explícitas de protesto que não são observadas facilmente, que são silenciosas porque os indivíduos que as praticam não se veem com força suficiente para enfrentar a dominação, quando há uma situação que evidencia essa situação de opressão, os indivíduos se reconhecem na atitude do outro e os protestos ganham dimensões que surpreendem os analistas, que não percebiam sinais de descontentamento com o regime dominante.

Há a construção de um discurso caracterizado como oculto que funciona como um combustível a uma ação coletiva, o sentimento individual a respeito de uma determinada estrutura de poder, seja estatal ou privada, é um sentimento que não é publicizado, mas que circula intersubjetivamente entre os membros de um grupo. A construção desse discurso é importante para a 
adesão dos membros do grupo a uma ação coletiva, pois é um período de introjeção de crítica ao sistema de dominação, no qual se constrói um sentimento de contrariedade à situação vivenciada. Esse tipo de discurso é mais relacionado a grupos que vivenciam sistemas de vigilância mais rígidos, mas não é exclusividade deles, é muito frequente perceber que tal discurso é construído em ambientes diversos, pois é uma forma do indivíduo sentir que seu sentimento em relação ao sistema dominante é compartilhado pelos demais membros do grupo, caso contrário ele se retrai e o discurso não ganha proporções intersubjetivas.

É só quando o discurso oculto é compartilhado em dimensões intersubjetivas que causa adesão quando alguém o publiciza pela primeira vez desafiando o poder e a autoridade, nesse momento ele corre o risco da rejeição, mas se aceito, instaura uma disputa simbólica entre desafiantes e desafiados, é um momento crucial para quem profere o discurso, como para todos que compartilham desse discurso.

0 ato inicial que quebra a superfície aparente do consentimento deve parte de sua força dramática ao fato de ser normalmente um passo irrevogável. Um subordinado que dê tal passo é, simbolicamente falando, um aventureiro que destrói a ponte que acaba de atravessar. Uma vez mais, o caráter público desse passo é uma parte essencial do seu poder de evocação (SCOTT, 2013, p. 284).

O desafio de um subordinado ao seu algoz é um passo irrevogável porque rompe o consentimento da dominação. Ele se aventura porque desafia o poder, e ao desafiá-lo, põe em risco sua própria existência, pois nada lhe assegura a vitória, mas há algo que lhe impulsiona a enfrentar a autoridade instituída, a sua dignidade, a sua verdade. É em nome de uma verdade silenciada e compartilhada por muitos que alguém rompe o silêncio e instaura uma nova relação com o opressor, não mais de subserviência, mas de confronto e de disputa, que já vinha sendo travada ocultamente longe do opressor.

A partir desse momento se instaura, explicitamente, o conflito, o discurso oculto perde essa natureza e torna-se público, ele carrega em si um sentimento de verdade para quem o profere e para todos aqueles que compartilham do mesmo sentimento. A publicização do discurso oculto só é possível por ele representar a "verdade", a verdade de quem o expressa, que a partir do momento de sua revelação, se pretende também como verdade para muitos que tinham se silenciado diante da opressão. Agora a verdade do opressor será questionada, e o que antes era inquestionável corre o risco de ser contestada e refutada, pois uma nova leitura da realidade é posta em evidência, se contrapondo à estrutura de poder estabelecida.

Apesar de termos evitado expressamente empregar o termo verdade para caracterizar o discurso oculto, é por demais evidente que a declaração do discurso oculto na face do poder é normalmente experimentada, quer pelo orador, quer pelos que se encontram nas mesmas condições, como um momento em que a verdade é finalmente revelada em lugar de equívocos e mentiras (SCOTT, 2013, p. 284). 
A ação coletiva posta em curso pela publicização do discurso oculto evidencia o embate entre concepções de verdade, de um lado estão os desafiantes, do outro, os desafiados. A vitória dependerá de vários fatores e as estratégias de luta serão fundamentais para ambos os lados, seja para quem contesta, seja para quem é contestado. Ao longo do embate surgirão as oportunidades e quem souber melhor aproveitá-las, provavelmente, será vencedor. Essas oportunidades se caracterizam como aspectos que fragilizam um dos grupos e abre espaço para a ação adversária.

Os desafiados agem sempre para desmobilizar os desafiantes, os grupos desafiantes têm a mobilização como sua principal fonte de força. A mobilização dos membros de um grupo depende de vários fatores, uma vez que os membros não respondem da mesma forma aos estimulo de determinado fator ou de determinada performance, "nunca se sabe qual portador físico vai atingir um indivíduo, portanto se tenta utilizar tantos quanto possível" (JASPER, 2016, p. 72), daí não existir uma relação mecânica entre o estímulo e à mobilização, fatores vão se confluindo para gerar uma mobilização favorável. Quando vários fatores confluem para a mobilização de um grupo em uma ação de contestação, diz-se que a estrutura de oportunidades políticas foi favorável, a qual é definida como “o conjunto dos elementos do ambiente e do contexto político exercendo uma influência positiva ou negativa sobre o engajamento em um protesto coletivo" (MATHIEU, 2002, p. 76)2 ${ }^{2}$ É ela que, geralmente, é responsável pelas vitórias dos movimentos sociais, neste caso, ela fortalece os desafiantes e fragiliza os desafiados.

A mobilização em torno de uma ação coletiva não ocorre de forma mecanicista em respostas a um interesse comum, o qual não é suficiente para que cada membro do grupo se mobilize. Nesse sentido, "o argumento clássico de Olson mantém a sua força. A presença de um interesse em obter um bem coletivo não basta para explicar a mobilização coletiva para aquele bem" (MELUCCI, 2001, p. 64), há mais elementos além do interesse comum responsáveis pela mobilização de um grupo. "A ação coletiva de um movimento é resultante de objetivos, recursos e limites, isto é, uma orientação finalizada que se constrói por meio de relações sociais no interior de um campo de oportunidades e de vínculos" (MELUCCI, 2001, p. 46). Não se pode aceitar a ideia de que apenas um fator seja responsável pela mobilização de um grupo, ela é decorrente de vários fatores, como já foi dito, e que cada um exerce sua força de influência, seja num aspecto coletivo, como individualmente.

O interesse comum, a construção de identidade coletiva e a solidariedade social se referem mais especificamente para a mobilização do grupo em si mesmo, são formas de motivar cada membro a participar da ação coletiva, são ações voltadas para o interior do próprio grupo. Já quando se fala em estrutura de oportunidades políticas, o foco sai do grupo em si mesmo para se direcionar ao exterior, às condições estruturais em que o sistema de poder está envolto. A estrutura de oportunidades 
políticas, por si só, não gera uma ação coletiva, será necessário que os membros de um grupo organizado possam aproveitar a oportunidade que surge e deflagrar a ação mobilizadora, a partir das fragilidades observadas.

A estrutura da oportunidade política é composta por seis propriedades de um regime, que são as seguintes:

1. a multiplicidade de centros de poder autônomos;

2. seu grau de abertura a novos atores;

3. a instabilidade dos alinhamentos políticos;

4. a existência de eventuais aliados de peso dos contestadores;

5. a medida que o regime reprime ou facilita a reivindicação coletiva;

6. as mudanças imprimidas pelos cinco itens anteriores (TILLY; TARROW, 2008, p. $106)^{3}$.

Os sinais de fragilidade ou robustez de um regime são evidenciados por essas propriedades, as quais vão facilitar ou dificultar a ação coletiva dos grupos opositores. Quando um sistema de poder se multiplica, evidentemente que sua força de contenção de protestos se enfraquece, o enfraquecimento de um regime abre possibilidade para novos atores se lançarem em ações contestatórias. Quando um sistema se divide em vários centros de poder, isso evidencia que o sistema de poder está em disputa, consequentemente, o alinhamento político deles se torna divergente. 0 conflito no interior do sistema de poder gera dissidência, que pode dar apoio ao movimento de contestação. 0 centro de poder se fragiliza e sua resposta aos protestos não possuem força suficiente para barrá-los, nesse caso a relação de poder se altera e os movimentos contestatórios ganham força em relação à estrutura de poder. Esses fatores se inter-relacionam e constituem a estrutura de oportunidades políticas, é nesse momento que a ação coletiva pode ganhar espaço e imprimir mudanças reformistas ou estruturais.

O sucesso da ação coletiva não será definido apenas pela estrutura de oportunidades políticas favorável aos desafiantes, é necessário que o grupo também tenha sagacidade para identificar as fragilidades do sistema e defina ações que possam explorar essas fragilidades. Caso o sistema não seja atingido em suas fragilidades, pode recompor sua unidade e combater fortemente os grupos de protestos. Segundo Tarrow, as pessoas agem impulsionadas pelas fragilidades do sistema e deixam de agir quando esse restringe suas ações, sendo que os fatores sociais são menos eficientes para a mobilização dos grupos. "O confronto é muito mais relacionado a oportunidades de ação coletiva - e limitado por restrições a ela - do que por fatores sociais e econômicos persistentes experimentados pelas pessoas" (TARROW, 2009, p. 99). Porém não se pode deixar de considerá-los, uma vez que eles

\footnotetext{
${ }^{3}$ La structure d'opportunité politique se composse des six propriétés suivantes d'um régime:

1. la multiplicité des centres autonomes de pouvoir qui s'y trouvent;

2. son degré d'ouverture à de nouveaux acteurs;

3. l'instabilité des alignements politiques du jour;

4. l'existence d'éventuels alliés de poid pour les contestataires;

5. la mesure dans laquelle le régime réprime ou au contraire facilite la revendication collective;

6. des changements importants intervenant dans les cinq domaines ci-dessus.
} 
dão subsídio à construção de uma narrativa que põe o sistema de poder diante de questões de moralidade e de justiça.

Não se pode negar que o regime de governo tem relação direta com a ocorrência da ação coletiva, uma vez que esta é mais frequente em regimes democráticos, uma vez que a própria democracia garante o direito à manifestação. É o grau de democracia e a capacidade de controle do estado sobre a população que influencia o surgimento de ações coletivas, assim as estruturas de oportunidades políticas surgem, com mais frequência, em regimes que possuem um alto grau de democracia e que o Estado possui pouco controle sobre a população; já os regimes não democráticos, que possuem uma capacidade forte de controle da população, excluem quase que totalmente a possibilidade de manifestação.

As duas variáveis de regime que mais importam na política do conflito são a capacidade do Estado e o seu grau de democracia. A capacidade é o que mede o impacto da ação do Estado sobre a população de seu território, sua distribuição, sua atividade, seus recursos [...].

A democracia é o que mede se as pessoas, sob a autoridade de um determinado Estado, gozam de direitos políticos amplos e iguais, e exercem uma influência direta sobre a política e as decisões públicas (através, entre outros mecanismos, de eleições abertas ou referendos) e possuem os meios para se proteger da arbitrariedade dos agentes do Estado, como policiais, juízes e funcionários públicos (TILLY; TARROW, 2008, pp. 102-103). ${ }^{4}$

Essas duas variáveis são importantes para caracterizar o Estado e compreender a sua tolerância aos movimentos reivindicatórios. A partir dessa caracterização é possível compreender os limites da ação coletiva dentro de determinado Estado. A relação entre ela e o Estado está definida pela estrutura do regime de poder, o regime se constrói a partir de uma concepção de cultura construída em seu interior, a qual é fundamentada ou não em princípios democráticos. Caso a democracia seja um valor fundamental compartilhado na sociedade, tem-se uma sociedade propícia a apoiar e participar de ações coletivas, isto porque o princípio democrático constitui elemento fundamental da construção cultural dessa sociedade.

A ação coletiva, neste caso, está relacionada com um sentimento democrático compartilhado não só pelos membros do grupo, mas também pelos indivíduos que pertencem à sociedade. Os valores democráticos fazem parte do habitus social e cultural que formam a identidade dos indivíduos pertencentes a essa sociedade ou cultura. A motivação para a ação coletiva se situa no indivíduo na medida em que sua individualidade é uma construção social que absorve o habitus sociocultural

\footnotetext{
${ }^{4}$ Les deux variables en matière de régime qui importent le plus en politique du conflit sont la capacité de l'État et le degré de démocratie. La capacité est la mesure dans laquelle l'action de l'État a un impactt sur la population de son territoire, sa répartition, son activité, ses ressources [...].

La dèmocratie est la mesure dans laquelle les personnes relevant de l'autorité d'un État donné jouissent de droits politiques larges et égaux, exercent une influence directe sur le personnel politique et les décisions publiques (par le biais, entre autres, d'élections ouverts ou de référendums) et ont les moyens de se protéger de l'arbitraire des agents de l'État tels que policiers, juges et fonctionnaires.
} 
coletivo transformando sua individualidade numa forma de individualidade coletiva, daí sua disposição à ação coletiva está intimamente relacionada ao habitus sociocultural assimilado e vivenciado pelo indivíduo na sua prática social, sendo que este habitus é um referencial da sua posição na estrutura social de poder. "Toda tomada de posição sobre social se ordena e se organiza a partir de uma determinada posição nesse mundo, isto é, do pondo de vista da conservação e do aumento do poder associado a essa posição" (BOURDIEU, 2013, pp. 35-36). A ação coletiva não se constrói fora das relações de poder, sendo que os desafiantes ocupam um espaço de poder dentro da estrutura social, e é dessa posição que surge sua capacidade de protesto, que tem como objetivo a manutenção ou a aquisição de poder.

Em todo confronto, o campo em disputa é o poder, cada grupo luta para manter ou adquirir poder. A vitória de um grupo no confronto é avaliada a partir desse objetivo, sendo que o resultado pode imprimir uma reorganização das estruturas sociais de poder em virtude da aquisição ou perda de poder dos grupos em confronto. Só há confronto entre grupos que possuem algum quantitativo de poder, por isso ocupam uma determinada posição social e detém algum capital cultural, é justamente esse capital que lhes possibilita fazer parte de uma mobilização em apoio ou como membro de um grupo social. "O confronto político não nasce da cabeça dos organizadores, mas está culturalmente inscrito e é socialmente comunicado. As convenções aprendidas do confronto fazem parte de uma cultura pública da sociedade" (TARROW, 2009, p. 39), então, a construção de um confronto político não se dá unicamente por desacordo com situações pontuais acerca de determinada situação, é algo construído culturalmente num processo histórico que forma em cada um a disposição para o confronto político.

Há, dessa forma, a construção de um habitus cultural que predispõe o indivíduo à ação, pois “o habitus não é senão essa lei imanente, lex insita inscrita nos corpos por histórias idênticas, que é a condição não somente da concertação das práticas, mas também das práticas de concertação (BOURDIEU, 2009, p. 98). 0 habitus é construído num processo histórico, não é algo que insurge do dia para a noite, é um processo de construção de uma consciência coletiva assimilada pelo indivíduo, assim a ação coletiva se constitui também como um processo de assimilação de táticas e estratégias retiradas de um repertório histórico de ação coletiva, mas que é necessário as adequações às exigências do momento da ação.

Mais uma vez se reforça a noção de que a mobilização em torno da ação coletiva não se dá simplesmente pela existência de uma insatisfação com uma determinada situação ou realidade, é necessária a existência da confluência de vários fatores que podem levar uma insatisfação localizada a gerar uma situação de confronto político. É importante destacar mais um fator de mobilização importante para a deflagração de uma ação coletiva, que é a confiança compartilhada entre os membros do grupo e destes com as lideranças. 0 surgimento de desconfianças é um fator de desmobilização da ação coletiva. 
A coordenação da ação coletiva depende da confiança e da cooperação geradas entre os participantes por meio de entendimentos e identidades compartilhados - ou, para usar uma categoria mais ampla, dos quadros interpretativos da ação coletiva que justificam, dignificam e animam a ação coletiva (TARROW, 2009, p. 40).

A confiança não se resume a um aspecto moral, mas também ao aspecto intelectual, ou seja, a confiança nas análises das lideranças, nos quadros interpretativos propostos por elas. Esses dois aspectos da confiança são importantes para se construir uma identidade coletiva capaz de superar os desafios impostos pelo processo de ação coletiva. A confiança possui um princípio unificador, pois possibilita que os membros de um grupo compartilhem sentimentos e concepções em torno de uma determinada concepção de mundo e, portanto, possam empreender uma luta norteada por esses princípios e ideais.

A mobilização em torno da ação coletiva é um processo que se constrói antes do surgimento ou da deflagração da ação coletiva e durante o seu curso. Ela não ocorre deslocada de uma cultura e de uma história, muito menos de uma realidade social construída com cisões que alimentam o conflito em torno de redistribuições e reconhecimentos. Uma ação coletiva é construída ao longo de um processo histórico e cultural em resposta a uma realidade social que não consegue conciliar os interesses dos inúmeros grupos que a compõem. Da mesma forma que a irrupção de uma ação coletiva foi germinada em processos históricos e culturais construídos por gerações anteriores, seus efeitos são projetados para o futuro. Isso não quer dizer que exista um processo evolutivo da ação coletiva, mas apenas que seus efeitos são projetados para o futuro, seja de avanços ou retrocessos. Os repertórios da ação coletiva são construídos e reconstruídos ao longo dos processos de contestação e suas inovações podem ter resultados positivos ou negativos, mas não deixam de agregar elementos de análise e compreensão das ações coletivas.

\section{AS INOVAÇõES NO REPERTÓRIO DA AÇÃo COLETIVA}

Uma ação coletiva não é a cópia de outra ação coletiva, elas possuem aspectos distintivos entre si, seja de tempo, de espaço ou de cultura, para ficar apenas nesses três aspectos. Isso não quer dizer que elas se constroem sem diálogos entre si. Uma ação coletiva dialoga com as ações que já ocorreram, com as contemporâneas e projetam suas vozes para as que virão. Os repertórios da ação coletiva não são monopólios de quem os cria e para cada ação um repertório pode possuir um significado distinto do que possuiu antes, isto porque o sistema simbólico de uma ação coletiva muda em relação a outra, com isso cada repertório ganha e perde significados quando é transportado de uma ação para outra.

Os movimentos usam formas diferentes de ação coletiva, isoladas e combinadas, para ligar as pessoas entre si e aos opositores, apoiadores e terceiros. Eles tiram vantagem 
da familiaridade cultural dessas formas de ação e inovam em torno de suas margens para inspirar a imaginação dos apoiadores e gerar medo entre os opositores. (TARROW, 2009, p. 250).

As inovações nos repertórios ocorrem dentro de um sistema simbólico, uma vez que seu objetivo é interagir com os indivíduos de dentro e de fora do grupo para convencê-los a participar ou apoiar a ação. Os repertórios são uma forma de dialogar que possuem significado ambíguo, uma vez que os receptores da mensagem não estão situados na mesma posição social. Aos apoiadores, a mensagem gera apoio; aos opositores, medo. 0 repertório da ação coletiva é o catalizador dos sentimentos que fortalecem ou enfraquece o movimento, daí a importância de sua escolha e de sua execução.

O repertório se insere dentro de um sistema simbólico, que não é estático e transforma-se continuamente, seja a partir da transformação dos símbolos e significados, seja a partir das transformações estruturais. 0 repertório faz parte de um sistema político, o qual não está fora do sistema simbólico, as transformações do repertório da ação coletiva são uma forma de adaptação às transformações políticas, como também às transformações estruturais do sistema, sendo que objetivam manter a interação dentro do sistema de representações. "Os repertórios evoluem de acordo com dois tipos principais de processos: seja no turbilhão desses períodos em que toda a política se move muito rapidamente, seja por uma série de modificações modestas de elementos estruturais" (TILLY; TARROW, 2008, p. 49).5 As transformações tanto no campo da política, como dos elementos estruturais impulsionam as transformações do repertório da ação coletiva, nessas transformações ocorrem as inovações, as quais não se caracterizam como uma simples transformação, pois ao mesmo tempo que dialogam com repertórios antigos procuram imprimir uma prática inédita.

As transformações políticas intensas são as principais responsáveis pelas inovações do repertório da ação coletiva, uma vez que a ação do movimento não pode se desconectar dessas transformações, mas também não pode simplesmente seguir o curso das transformações sem interferir nelas, sem redirecioná-las a favor de seus objetivos, isso impõe uma dinâmica intensa de interação e mobilização. "Os períodos de rápida mudança política revelam sequências de inovação nos repertórios, que por sua vez explicam as flutuações da atividade do movimento" (TILLY; TARROW, 2008, p. 49)6 É no decorrer desse processo de transformação política que o embate entre desafiantes e desafiados se intensifica e o resultado favorável aos desafiantes será definido pelo sucesso das táticas de inovações empreendidas na ação coletiva.

A disputa entre desafiantes e desafiados é definida como uma batalha de estratégias, onde um tenta surpreender o outro, tanto nas táticas de ataque, quanto nas de defesa, sendo que as que não

\footnotetext{
${ }^{5}$ Les répertoires évoluent selon deux grands types de processus: soit dans le tourbillon de ces périodes oú toute la politique bouge très vite, soit por une suite de modifications modestes d'élements structurels.

${ }^{6}$ Les périodes de changement politique rapide font apparaître des séquences d'innovation dans les répertoires, lesquelles à leur tour expliquent les fluctuations de l'activité du mouviment.
} 
funcionam são descartadas da ação. "Os manifestantes abandonam as táticas que não se ajustam às arenas que encontram e abraçam as que se ajustam. Encontram as chaves adequadas para abrir as fechaduras disponíveis" (JASPER, 2016, p. 58). As táticas certas no momento oportuno abrem o caminho para a vitória, mas a questão se coloca em encontrar a tática adequada para o momento certo, uma vez que as oportunidades são dinâmicas e as tomadas de posição devem ser ágeis e precisas e muito frequente não o são.

0 protesto seria fácil se sempre houvesse uma coisa certa a fazer em qualquer situação. Mas há sempre muitas coisas a fazer e, com frequência nenhuma delas é especialmente boa. A ação estratégica é cheia de dilemas e acordos: toda opção é promissora de determinadas maneiras, mas arriscadas de outras (JASPER, 2016, p. 59).

Construir uma ação coletiva não é como seguir as instruções de uma receita de bolo, não há ingredientes definidos para os objetivos que se deseja, há sempre possibilidades de reações contrárias que desviam os resultados para dimensões não avaliadas, por isso a ação coletiva exige de seus organizadores que tomem posições rápidas, sem muito tempo para reflexões e análises, as tomadas de posições devem ocorrer no processo de construção da ação coletiva, mas nem por isso devem ser decididas aleatoriamente, há sempre um repertório a ser consultado para subsidiar melhor as estratégias que serão implementadas.

O repertório da ação coletiva, historicamente construído, não deve ser desprezado, porém deve-se analisar e adequar a melhor ação para ser utilizada na ocasião. Mas não é só isso, os organizadores ou líderes da ação coletiva devem se dá a oportunidade de ousar, criar novas táticas de luta, porém tudo isso é arriscado, uma vez que um novo repertório suscita ações e reações nunca antes experimentadas, os efeitos podem ser positivos, mas também negativos, uma vez que não se pode eliminar as consequências de uma ação, elas virão, se positivas aos desafiantes a estratégia foi acertada, mas se negativa, foi um equívoco. São os acertos e os equívocos que definem o curso de uma ação coletiva, sendo que as dificuldades em reagir a uma ação inovadora se apresentam para os dois lados, por isso a inovação sempre reserva surpresas para a ação coletiva, mas é importante que ela ocorra, mesmo que não tenha resultados positivos, mas poderá ser aperfeiçoada por ações coletivas que virão ou descartadas como estratégias de ação.

Os manifestantes não ficam simplesmente olhando em volta em busca da chave adequada. [...], eles também inventam novas táticas, tirando vantagem das mudanças nas arenas ou criando outras. A criatividade da ação é empolgante, mas difícil de prever, e os estudiosos não têm se saído muito bem em explicá-la. Um ato criativo frequentemente ocorre quando os atos normais são obstruídos, embora o resultado também possa ser apenas um procedimento desesperado (JASPER, 2016, p. 59).

A inovação surge quando o uso dos repertórios convencionais da ação coletiva é bloqueado ou visto como ineficiente naquele momento. Os manifestantes criam novas táticas de luta para tentar 
por fim ao impasse, uma vez que quanto mais o movimento se prolonga mais custosa fica a ação e o poder de resistência pode diminuir em decorrência do cansaço imprimido aos manifestantes. Os opositores sabem disso e usam de todos os mecanismos para bloquear os efeitos dos repertórios usados pelos desafiantes, essa luta é estratégica, envolve a capacidade de comunicação e diálogo com os indivíduos que estão dento e com os que estão fora do conflito.

Os meios de comunicação são um forte elemento envolvido na disputa, como também se constituem com um forte potencial de inovação da ação coletiva. 0 uso das redes sociais para fazer contraponto às informações vinculadas pelos meios de propaganda dos desafiados é uma forma de disputar a consciência tanto dos que estão envolvidos diretamente no conflito, como dos que não estão. Assim, as inovações podem ocorrer na forma de comunicação e diálogo dos desafiantes com o público em geral, mas especificamente também com os próprios membros dos grupos.

A cobertura midiática de uma ação coletiva é um forte elemento de divulgação das ideias dos manifestantes e as inovações metodológicas visam também chamar atenção da mídia e de sua cobertura, fazendo com que ela não tenha meios de recusar a noticiar as manifestações, a exemplos das manifestações em Belgrado que puseram o regime de Slobodan Milosevic abaixo.

Quando a polícia exigiu que apenas pedestres comuns usassem as ruas do centro de Belgrado, milhares de pessoas apareceram passeando com seus cachorros ou fingindo ir para o trabalho; quando a mídia, controlada pelo Estado, recusou-se a divulgar os protestos, os participantes de passeatas fizeram fila e passaram por suas sedes todas as noites, tendo assim acesso à mídia internacional (TARROW, 2009, p. 124).

As inovações surgem quando, geralmente, os manifestantes são impedidos de fazer suas manifestações convencionais ou quando a mídia se recusa a noticiar seus protestos, essa recusa, no caso acima, foi superada com uma ação criativa de ir ao encontro da mídia em vez de esperar que esta fosse ao encontro dos manifestantes. Todas as formas de manifestações, inclusive as inovações, objetivam a interação entre os desafiantes e os desafiados, pois é em consequência dessa interação que os protestos se intensificam ou diminuem de intensidade, sendo que "a inovação nas formas de ação coletiva resulta da interação entre aqueles que protestam e seus oponentes" (TARROW, 2009, p. 135). Quanto mais a interação se torna difícil, mais se intensificam formas que reestabeleçam essa interação para que o protesto chegue ao final, computando suas vitórias e derrotas para ambos os lados.

As inovações da ação coletiva são uma forma de avançar na solução dos impasses provocados por ela, é uma forma de avançar na luta e pôr fim ao protesto, seja conseguindo os objetivos traçados ou negociando concessões, ajustando as reivindicações ao quantitativo de força que ainda é capaz de reunir. As inovações, radicais ou não, são lançadas quando as formas convencionas de protestos não inspiram resultados animadores, elas são uma forma de continuidade e longevidade da própria cultura da ação coletiva, sem elas a ação coletiva tenderia a desaparecer, pois seus repertórios não ofereceriam mais risco aos desafiados, daí a importância das inovações, sem desprezo pelas formas 
tradicionais de protesto que cumpriram e ainda cumprem função importante nos processos de ação coletiva.

\section{CONSIDERAÇÕES FINAIS}

A ação coletiva imprime mudanças na estrutura simbólica, econômica e social de uma sociedade, algumas mais outras menos, mas todas, de alguma forma, deixam alguns significados importantes para a sociedade como um todo. A ação coletiva não surge do nada, há sempre motivações que levam os indivíduos a se mobilizarem, sejam de natureza econômica, política, social, moral ou cultural. Mas não se pode esquecer que elas são próprias de regimes democráticos, mas não exclusivos deles, uma vez que os regimes autoritários podem ser derrotados pela ação coletiva que se origina no interior do regime, apesar da repressão e dos olhos do poder. Por outro lado, nem toda ação coletiva segue o caminho da democracia, algumas delas seguem o caminho oposto.

Uma ação coletiva põe em evidência cisões estruturais, sociais e culturais que antes não eram visíveis, eram vozes que não eram ouvidas, indivíduos que não eram vistos e que passam a ser vistos e ouvidos. A ação coletiva tenta mudar o foco dos holofotes para problemas que eram soterrados, sendo que sua função é de escavá-los e fazê-los visíveis à sociedade e às estruturas de poder, não dando a estas a oportunidade de negá-los, com isso ela imprime uma nova dinâmica à sociedade, fazendo com que seus olhos voltem para si mesma e enxergue suas entranhas, que não estão na superfície.

Essas entranhas, muitas das vezes, têm revelado vieses não democráticos, para não dizer fascistas. Constantemente têm surgido, em sociedades relativamente democráticas, ações coletivas reacionárias em relação às liberdades religiosas, de gênero e políticas, enfim, contra os preceitos que sustentam a democracia: os direitos humanos e as liberdades individuais e coletivas. Desta forma, a "natureza" de uma ação coletiva é construída por seus atores e pode ter resultados que fortaleçam os princípios democráticos ou, pelo contrário, enfraqueça-os. Por isso, a democracia, que nunca alcançou a sua plenitude, constantemente se vê ameaçada por suas fragilidades internas que ainda não soube superá-las, isto é um sintoma de que ela ainda não existiu, de fato, entre nós.

Essas lacunas democráticas, que possibilitam o surgimento de movimentos antidemocráticos com força suficiente para imprimir derrotas à democracia, devem ser mais bem estudadas para que se identifiquem os fatores que fortalecem esses movimentos, os quais parecem ser impensados em sociedades que começam seguir um percurso mais democrático, mas que surpreendem e irrompem com força suficiente para imprimir rupturas democráticas e dar um novo rumo à sociedade. A democracia ainda não conseguiu criar um antídoto contra o autoritarismo, talvez porque ela não se efetivou de fato, por isso é importante compreender as suas fragilidades para que se fortaleçam os alicerces democráticos, caso contrário, podem surgir, como de fato têm surgido, movimentos que buscam destruir conquistas democráticas, defendendo o autoritarismo como sendo capaz de 
solucionar problemas ainda pendentes e que não foram enfrentados nas sociedades relativamente democráticas, como a corrupção e a violência.

É importante também compreender os efeitos das redes sociais para o processo de mobilização da ação coletiva, bem como o próprio ativismo nas redes sociais, que é uma forma contemporânea de mobilização que dispensa a participação física dos ativistas, uma vez que a mobilização se dá no ambiente virtual. Essa nova forma de ativismo carece de análise para que se dimensionem os efeitos dessa nova forma de contestação. A ação coletiva tradicional não pode se furtar à utilização das redes sociais, mas até que ponto o ativismo virtual pode substituir o manifesto de rua? Quais as divergências e convergências do ativismo digital com os movimentos tradicionais, que buscam sempre a mobilização física como forma de se contrapor ao sistema de poder, enquanto aquele busca o embate virtual nas redes sociais? As novas formas de mobilização e de protestos surgidas com a revolução digital é um campo aberto à análise que precisa ser objetivado através de pesquisas que aprofundem o conhecimento dessas novas formas de mobilização e atuação.

\section{REFERÊNCIAS}

ALONSO, Angela. As teorias dos movimentos sociais: um balanço do debate. São Paulo: Lua Nova, 2009.

BITOUN, Jan. Movimentos Sociais e a Cidade: questões relevantes para a geografia

urbana. In: FISCHER, Tânia. (org). Poder Local: Governo e Cidadania. Rio de Janeiro:

Fundação Getúlio Vargas, 1993.

BOLTANSKI, Luc. El amor y la Justicia como competências: tres ensayos de sociología de la acción. Madrid: Paidós, 2001.

BOURDIEU, Pierre. Homo academicus. Tradução Ione Ribeiro Valle e Nilton Valle. Florianópolis: Editora da UFSC, 2013.

BOURDIEU, Pierre. O senso prático. Tradução Maria Ferreira. Petrópolis: Vozes, 2009.

FERNADES, Bernardo Mançano. Movimento social como categoria geográfica. Revista Terra Livre, São Paulo, n. 15, p. 59-85, 2000.

FOUCAULT, Michel. Microfísica do poder. Organização Roberto Machado. São Paulo: Graal, 2013.

FRASER, Nancy. Reconhecimento sem ética? Tradução Ana Carolina Freitas Lima e Mariana Prandini Fraga Assis. São Paulo: Lua Nova, p. 101138, 2007.

GONÇALVES, Carlos Walter Porto. A geograficidade do social: uma contribuição para o debate metodológico para os estudos de conflitos e movimentos sociais na América Latina. Revista Eletrônica da Associação dos Geógrafos Brasileiros, Seção Três Lagoas MS, V 1, n. 3, ano 3, p. 5-26, maio, 2006.
HALL, Stuart. A identidade cultural na pósmodernidade. Tradução Tomaz Tadeu da Silva e Guaracira Lopes Louro. Rio de Janeiro: DP\&A, 2006.

HONNETH, Axel. Luta por reconhecimento: a gramática moral dos conflitos sociais. Tradução Luiz Repa. São Paulo: Editora 34, 2009.

JASPER. James M. Protesto: uma introdução aos movimentos sociais. Tradução Carlos Alberto Medeiros. Rio de Janeiro: Zahar, 2016.

MATHIEU, Lilian. Rapport ao politique, dimensions cognitives et perspectives pragmatiques dans l'analyse des mouvements sociaux. Revue Française de Science Politique, v. 52, n. 1, p. 75100, 2002.

MELUCCI, Alberto. A invenção do presente. Tradução Maria do Carmo Alves do Bonfim. Petrópolis: Vozes, 2001.

OLSON, Mancur. A lógica da ação coletiva: os benefícios públicos e uma teoria dos grupos sociais. Tradução Fabio Fernandez. São Paulo: Editora da Universidade de São Paulo, 1999.

SCOTT. James C. A dominação e a arte da resistência: discursos ocultos. Tradução Pedro Serra Pereira. Lisboa: Letra Livre, 2013.

SOUZA, Marcelo Lopes de. A prisão e a ágora: reflexões em torno da democratização do planejamento e da gestão das cidades. Rio de Janeiro: Bertrand Brasil, 2006.

TARROW, Sidney. $O$ poder em movimento: movimentos sociais e confronto político. Tradução de Ana Maria Sallum. Petrópolis: Vozes, 2009. 
TILLY, Charles; TARROW, Sidney. Politique(s) $d u$ conflit: de la grève à la révolution. Traduit de l'anglais (États-Unis) par Rachel Bouyssou. Paris: Presses de Sciences Po, 2008.

THOMPSON, E. P. Costumes em comum: estudos sobre a cultura popular tradicional. Tradução
Rosaura Eichemberg. São Paulo: Companhia da Letras, 1998.

TOURAIENE, Alan. Na fronteira dos movimentos sociais. Rev. Sociedade e Estado, Brasília, v. 21, n. 1, p. 17-28, jan/abr 2016. 